DOI 10.37882/2223-2982.2021.05-2.21

\title{
ВЛИЯНИЕ КОМПЛЕКСНЫХ УРОКОВ ФИЗИЧЕСКОЙ КУЛЬТУРЫ НА ФИЗИЧЕСКУЮ ПОДГОТОВЛЕННОСТЬ УЧАЩИХСЯ СРЕДНЕГО ШКОЛЬНОГО ВОЗРАСТА
}

\section{THE INFLUENCE OF COMPLEX \\ PHYSICAL EDUCATION LESSONS ON \\ THE PHYSICAL FITNESS OF STUDENTS OF SECONDARY SCHOOL AGE}

Yu. Melnikov

N. Feofilaktov

Summary: The article reflects the results of the influence of complex physical culture lessons in general education schools on the level of physical fitness of secondary school age students. Comprehensive lessons are based on previously mastered exercises from sports games, athletics, gymnastics and skiing. They allow you to successfully combine training in the technique of motor actions with the development of motor qualities.

Keywords: students, physical culture, physical fitness, complex lesson, sports games, gymnastics, skiing preparation, athletics, level.

\section{Актуальность}

$\Phi$ изическая подготовленность - важный компонент здоровья, а ее улучшение - одна из главных задач физического воспитания в школе [1,2]. Хорошая физическая подготовленность является основой высокой работоспособности во всех видах учебной деятельности учащихся. Школьники с хорошей физической подготовкой успешнее справляются с задачами обучения, чем учащиеся с низким уровнем двигательного развития $[3,4]$.

По данным ряда авторов [3,4], к причинам снижения интереса к уроку физической культуры следует отнести однообразие содержания учебной программы, которая не учитывает возрастные изменения мотивации и интересов учащихся. Поэтому главной проблемой в школе была и остается проблема поиска новых средств, методов, форм повышения физической подготовленности и интереса к уроку физической культуры[2,3].

Известно, что переход от одного вида спорта к другому (по четвертям) нарушает гармоничность физической подготовки, ее всесторонность. Каждый вид спорта, его упражнения имеют свою яркую специфичность, а их специальная физическая подготовка дает спортивный результат только в конкретном виде спорта. Поэтому смена видов упражнений по четвертям ведет к одно-
Мельников Юрий Александрович

К.п.н., дочент, ФГБОУ ВО «Удмуртский государственный университет», г.Ижевск pffkksi@mail.ru

Феофилактов Николай Зотович доцент, ФГБОУ ВО «Удмуртский государственный университет», г. Ижевск, feofilaktov.nikolay@gmail.ru

Аннотация: В статье отражены результаты влияния комплексных уроков физической культуры в общеобразовательной школе на уровень физической подготовленности учащихся среднего школьного возраста. Комплексные уроки построены на освоенных ранее упражнениях из спортивных игр, легкой атлетики, гимнастики и лыжному спорту. Они позволяют удачно сочетать обучение технике двигательных действий с развитием двигательных качеств.

Ключевые слова: учащиеся, физическая культура, физическая подготовленность, комплексный урок, спортивные игры, гимнастика, лыжная подготовка, легкая атлетика, уровень.

бокому развитию отдельных возможностей человека, а если учесть, что длительность воздействия разных видов спорта по времени ограничена четвертью, то положительные сдвиги в организме чрезвычайно малы.

Комплексные уроки [1,3,4] физической культуры позволяют избегать однобокости в физическом развитии, повышают интерес к урокам, дают положительный эффект протяжении всего учебного года. Поэтому, комплексные уроки являются наиболее актуальной формой проведения урока физической культуры в школе.

Цель исследования - разработка и экспериментальное обоснование методики применения комплексных уроков физической культуры на физическую подготовленность учащихся среднего школьного возраста.

\section{Методы исследования}

Для достижения поставленной цели использовались: анализ научно-методической литературы, педагогический эксперимент, тестирование, математико-статистическая обработка полученных данных.

Исследование проводилось с сентября 2019 по май 2020 года на базе МБОУ СОШ №84 г. Ижевска. Для решения поставленных задач, нами был проведен педагогический эксперимент. 
До начала эксперимента было проведено тестирование по определению физической подготовленности учащихся по следующим тестам: бег 30м, челночный бег 3×10м, шестиминутный бег, прыжок в длину с места, метание набивного мяча, подтягивание из виса лежа на низкой перекладине (девочки), подтягивание из виса на высокой перекладине (мальчики), пресс, сгибание и разгибание рук в упоре лежа, наклон вперед. Показанные результаты считаются исходными.

Исходя из результатов тестирования, сформированы контрольная (КГ) и экспериментальная (ЭГ) группы по 17 учащихся в каждой группе, по 10 мальчиков и 7 девочек соответственно. КГ занималась по традиционной программе физического воспитания учащихся 1-11 классов с направленным развитием двигательных способностей (В.И. Лях). ЭГ занималась по разработанной нами методике, которая основана на проведении комплексных уроков с дополнительным включением упражнений из смежных разделов не выходя за рамки традиционной программы.

В течение эксперимента проведено пять контрольных срезов в обеих группах после прохождения занятий легкой атлетикой, спортивными играми, гимнастикой, лыжной подготовки и легкой атлетики. По результатам определяли динамику изменений уровня физической подготовленности учащихся.

На начало эксперимента уровень физической подготовленности в КГ составил: «ниже среднего» 23,5\%, «средний» уровень 70,6\% и 5,9\% «выше среднего». В ЭГ учащиеся с уровнем «ниже среднего» составили 29,4\%, со «средним» уровнем - 70,6\%. Учащихся с «низким», «выше среднего» и «высоким» уровнем не выявлено. Это свидетельствует о том, что в обеих группах преобладает «средний» уровень физической подготовленности.

\section{Результаты и их обсужАение}

Полученные результаты сравнительного анализа физической подготовленности учащихся среднего школьного возраста показали, что средний результат КГ в беге на 30м в начале эксперимента составил 5,23 $\pm 0,08$ с, а в

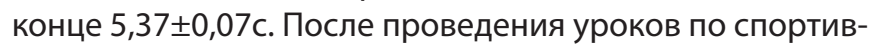
ным играм, результат ухудшились на 0,03с, это связано с использованием на уроках большой доли обучения техническим элементам, что снижает моторную плотность урока.

Низкая моторная плотность на традиционных уроках гимнастики и применение средств в учебном процессе только из этого раздела, также привели к изменению быстроты учащихся в худшую сторону $(0,25 c)$. Уроки лыжного спорта в основном были ориентированы на изучение способов передвижения на лыжах, т.е. носили обучающий характер. Поэтому по результатам четвертого среза развития быстроты не наблюдается. После раздела «Легкая атлетика» в КГ результаты улучшились на 0,15c, но не превысили исходный уровень т.к. большее внимание уделялось изучению техники двигательных действий. Результат улучшился на 0,14с и составил $2,7 \%$. Результат достоверный при $\mathrm{p}<0,05$.

В ходе исследования обнаружено, что результат ЭГ в беге на 30м в начале эксперимента составил 5,3 $\pm 0,07$,

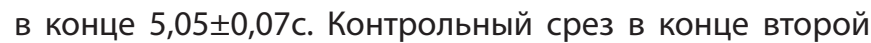
четверти показал улучшение результата на 0,1с. Наряду с изучением материала по спортивным играм, для развития быстроты было использовано больше упражнений из раздела легкой атлетики. После прохождения раздела «Гимнастика» результат улучшился на 0,02c. Это свидетельствует о том, что наряду с обучением элементам гимнастики, была возможность широкого применения упражнений для развития быстроты из разделов «Спортивные игры» и «Легкая атлетика». После раздела «Лыжная подготовка» результаты ухудшились на 0,1с. Спад в развитии быстроты в этот период закономерен. После раздела «Легкая атлетика» результаты улучшились на 0,23с, потому что использовались разнообразные подвижные и спортивные эстафеты. Результат в группе по окончании эксперимента улучшился на 0,25c, что составило 4,7\%. Результат достоверный при р <0,05.

Средний результат КГ в челночном беге $3 \times 10 \mathrm{M}$ в на-

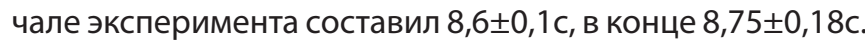
После уроков по спортивным играм наблюдается улучшение результатов, но не столь явное, всего лишь на 0,1с. Большая часть времени уделялась изучению техники игры, в ущерб развитию физических качеств учащихся. После уроков гимнастики, координационно-скоростные способности резко ухудшились на 0,2c, а уроки по лыжному спорту также не смогли их улучшить. Средства и методы, используемые на уроках по легкой атлетике, смогли, но едва заметно улучшить результаты в челночном беге $(0,05 c)$. Уроки носили в основном обучающий характер. Результат по окончании эксперимента улучшился на 0,15 с. и составил $1.7 \%$. Результат достоверный при $\mathrm{p}<0,05$.

Было выявлено, что результат челночного бега 3×10м. в начале эксперимента в ЭГ составил $8,8 \pm 0,1$, в конце $8,25 \pm 0,1$. После уроков, где решались основные задачи по спортивным играм и гимнастике, результаты заметно выросли на 0,2c и 0,05с соответственно. В содержание уроков были включены игры и игровые задания, направленные на развитие скоростных и координационно-скоростных способностей. Четвертый срез показал небольшое ухудшение результатов в челночном беге на 0,05c. Это закономерно, так как в данный период наряду с формированием двигательного навыка по лыжному спорту, происходило активное развитие специальной выносли- 
вости. После легкой атлетики результаты улучшились, так как наряду с обязательным обучением техническим элементам метания и прыжков, для развития координационно-скоростных способностей применялись спортивные игры, подвижные и игровые задания. Итоговый результат улучшился на 0,55с и составил 6,25\%. Результат достоверный при р <0,05.

Результат КГ в прыжках в длину с места до и после

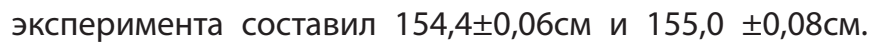
соответственно. После изучения раздела «Спортивные игры» результат в прыжках в длину ухудшился на 0,4см. Это можно объяснить использованием большой доли обучения технике на уроках баскетбола, из-за чего снижается его общая и моторная плотность. После раздела «Гимнастика» результат увеличился на 2см, за счет силовых упражнений на гимнастических снарядах. Но прирост небольшой, так как специального развития взрывной силы на уроках не было. Уроки по лыжному спорту значительно снизили дальность прыжка на 4,2см. Так как на них в основном решались образовательные задачи и воспитание выносливости. В конце года, после легкой атлетики, результат улучшился на 0,6см, но по сравнению с исходными показателями, изменения незначительные. Это связано с использованием большого количества времени на обучение отдельным элементам легкой атлетики, в ущерб развитию физических качеств. Конечный результат улучшился на 0,6 cм (0,4\%). Результат недостоверный при $\mathrm{p}<0,05$.

Хочется отметить и то, что в ЭГ результат в прыжках в длину с места, оценивающий развитие взрывной силы на начало и конец эксперимента составил $158,8 \pm 5,4$ см. и $171,8 \pm 5,2$ см. После раздела «Спортивные игры» результат улучшился на 4см, так как для развития физических качеств, применялись упражнения из раздела «Легкая атлетика». После раздела гимнастика, результат вырос на 7,9см. В этот период для развития взрывной силы применяли упражнения из легкой атлетики и игровые задания. После лыжного спорта снижение взрывной силы не произошло, в виду того, что после уроков на улице, в спортзале мы выполняли упражнения, укрепляющие мышцы ног, туловища. После легкой атлетики произошло заметное улучшение в показателях взрывной силы. Это говорит об оптимальном использовании условий внешней среды. Итоговый результат улучшился на 13 см. и составил 7,6\%. Результат достоверный при $\mathrm{p}<0,05$.

Средний результат КГ в метании набивного мяча в начале эксперимента составил $6,1 \pm 0,17 \mathrm{M}$, а в конце $6,1 \pm 0,15$ м. Объясняется это тем, что на традиционных уроках по спортивным играм развитию мышц туловища уделяется небольшое количество времени. После лыжного спорта происходит снижение результата на $35 \mathrm{~cm}$. В этот период основное внимание уделялось технике передвижения на лыжах. На уроках легкой атлетики применяли упражнения для укрепления мышц верхнего плечевого пояса. Результат увеличился, но всего на 10см. По окончанию эксперимента результат не отличается от исходного. Прирост составил 0\%. Результат не достоверный при $\mathrm{p}>0,05$.

Средний результат ЭГ в метании набивного мяча в начале эксперимента составил $6,3 \pm 0,17 \mathrm{M}$, а в конце $6,9 \pm 0,16 \mathrm{M}$. Заметный прирост отмечается после прохождения раздела «Спортивные игры» - 40см. В качестве подготовительных упражнений и для развития взрывной силы использовались различные упражнения с набивными мячами. Уроки из раздела «Гимнастика» повысили результат на 5см. Наряду с решением образовательных задач по гимнастике, применяли упражнения с набивными мячами для развития мышц туловища.

После раздела «Лыжный спорт» результат остался на прежнем уровне. Это ожидаемый результат, так как более целесообразно в этот период развивать специальную и силовую выносливость. После легкой атлетики результаты улучшились на 30см., так как применяли много упражнений для укрепления мышц верхнего плечевого пояса. Прирост составил 9,5\%. Результат достоверный при $\mathrm{p}<0,05$.

В ходе исследования удалось установить, что средний результат КГ в подтягивании на перекладине в

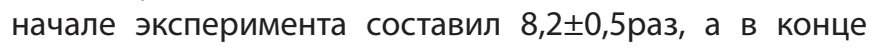
$8,2 \pm 0,7$ раза. После занятий спортивными играми сила мышц сгибателей рук снизилась на 0,2 раза т.к. нагрузка на данную группу мышц не носила развивающего характера вследствие низкой плотности урока и большой доли обучения элементам техники. Уроки гимнастики и лыжной подготовки не смогли улучшить абсолютную силу, так как было использовано недостаточно упражнений для ее развития, хотя занятия легкой атлетикой повысили показатели до исходного. Прирост составил 0\%. Результат не достоверный при р >0,05.

При анализе полученных данных ЭГ в тесте «Подтягивание на перекладине» выявили, что в начале эксперимента результат составил 7,6士0,6раза, а в конце $9,1 \pm 0,47$ раза. После прохождения раздела «Спортивные игры» результат улучшился на 1,1 раза. Это связано с тем, что для развития силы мышц сгибателей рук применяли упражнения с прогрессивно-возрастающим отягощением. После гимнастики результат улучшился, но не значительно. Применяли статические упражнения на гимнастических снарядах и упражнения с резиновыми бинтами. После лыжной подготовки результат практически остался без изменений. В процессе занятий по легкой атлетике с использованием нестандартного оборудования прирост составил 19,7\%. Результат достоверный при $р<0,05$. 
Средний результат КГ в поднимании туловища в начале эксперимента составил $37,8 \pm 1,0$ раза, а в конце $38,1 \pm 1,1$ раза. После занятий спортивными играми результат остался на исходном уровне. Вследствие того, что большую часть урока занимало обучение элементам техники, на развитие двигательных качеств оставалось мало времени. После традиционных уроков гимнастики результат заметно улучшился на 1,1 раза. Это закономерно, так как происходит активное развитие силы брюшных мышц, как за счет применения специальных упражнений, так и за счет статической работы на гимнастических снарядах. Но после лыжной подготовки сила брюшных мышц снова снижается до 37раз. После легкой атлетики результаты снова улучшаются на 1,1 раза. Прирост составил 0,8\%. Результат не достоверный при $\mathrm{p}>0,05$.

Результаты ЭГ в поднимании туловища в нача-

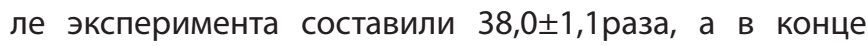
$43,5 \pm 0,7$ раза. После занятий спортивными играми сила мышц сгибателей туловища увеличилась на 1,2раза. Наряду с решением образовательных задач, для развития этой группы мышц применялись упражнения с набивными мячами. В том числе и метод прогрессивно-изменяющегося отягощения. В процессе решения образовательных задач по гимнастике продолжали применять метод прогрессивно-изменяющегося отягощения, увеличивая массу отягощения, быстроту перемещения груза, также применяли комплексы упражнений на шведской стенке и гимнастической скамейке. Результат улучшился на 1,3раза. После уроков по лыжной подготовке среднее количество подъемов туловища за минуту увеличилось на 1,3раза. После легкой атлетики результаты увеличились на 1,8 раза. Прирост составил 14,5\%. Результат достоверный при $\mathrm{p}<0,05$.

Важно, однако, обратить внимание на то, что средний результат КГ в тесте на гибкость в начале эксперимента

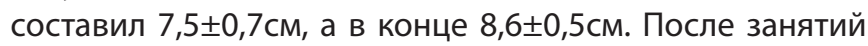
спортивными играми результат остался без изменений, потому что не на каждом уроке получалось включать упражнения на гибкость. На решение образовательных задач уходил большой объем времени, а, как известно, уже через недельный перерыв в занятиях гибкость начинает снижаться и быстро достигает исходных величин. После уроков гимнастики гибкость улучшилась на 0,6см. После прохождения раздела «Лыжный спорт» результаты снизились до исходного уровня. Уроки легкой атлетики поспособствовали увеличению гибкости на 0,5см, но за несколько уроков не возможно добиться явных результатов. Прирост составил 13,3\% . Результат достоверный при $\mathrm{p}<0,05$.

Оценивая полученные данные результатов ЭГ в тесте на гибкость выявили, что в начале эксперимента она составила $7,0 \pm 0,5$ см, а в конце $9,8 \pm 1$ см. После занятий спортивными играми результат улучшился на 0,5см. Для развития гибкости использовали динамические упражнения, которые обычно применяют на уроках гимнастики. Этим упражнениям следует отдавать предпочтение при малой подвижности суставов, так как они наряду с растягиванием «тормозящих» мышц способствуют развитию силы их антагонистов, благодаря укреплению которых и происходит увеличение амплитуды движений. После раздела «Гимнастика» развитие гибкости более значительно - 1,3см. Было использовано больше статических упражнений, которые повышают растяжимость мышц, ограничивающих размах движений. После лыжного спорта заметен небольшой прирост результата. После легкой атлетики результаты увеличились на 0,9см. Прирост составил 40,0\%. Результат достоверный при $\mathrm{p}<0,05$.

Средний результат КГ в тесте на выносливость в

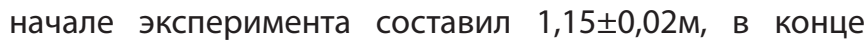
$1,18 \pm 0,03$ м. После занятий спортивными играми и гимнастикой результаты, ухудшились. После лыжного спорта заметен небольшой прирост на 0,04м, так как применяли передвижения на лыжах с равной интенсивностью. Но объем упражнений был значительно ниже, большую часть урока занимало обучение, поэтому сдвиг результатов небольшой. После легкой атлетики результат улучшился, но не значительно. Прирост составил 2,6\%. Результат не достоверный при р> 0,05.

В результате исследования оказалось, что показанный результат ЭГ в тесте на выносливость в начале

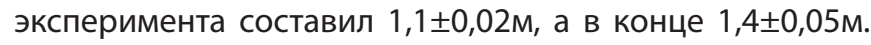
После занятий спортивными играми результат не изменился. После гимнастики произошел небольшой спад результатов. Традиционные уроки гимнастики носили обучающий характер и соответственно отличались низкой моторной плотностью. На лыжном спорте естественные условия позволяли развивать выносливость, и она значительно улучшилась на 0,2м. Это закономерно, так как выполняли разнообразные задания по прохождению на лыжах определенных дистанций с постоянной и переменной интенсивностью. После легкой атлетики результат улучшился, но не значительно. Прирост составил 27\%. Результат достоверный при $p<0,05$.

Нельзя сказать и о том, что в тесте «Сгибание и разгибание рук в упоре лежа» результат КГ в начале экспе-

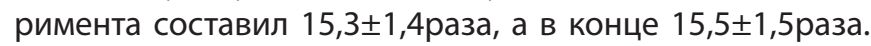
После занятий спортивными играми и гимнастикой результат практически не изменился. После лыжного спорта заметен небольшой спад результатов на 0,4 раза. После легкой атлетики результаты увеличились на 0,7 раза. Прирост составил 1,3\%. Результат не достоверный при $p>0,05$.

Отметим, что средний результат ЭГ в тесте «Сгибание и разгибание рук в упоре лежа» в начале эксперимента 


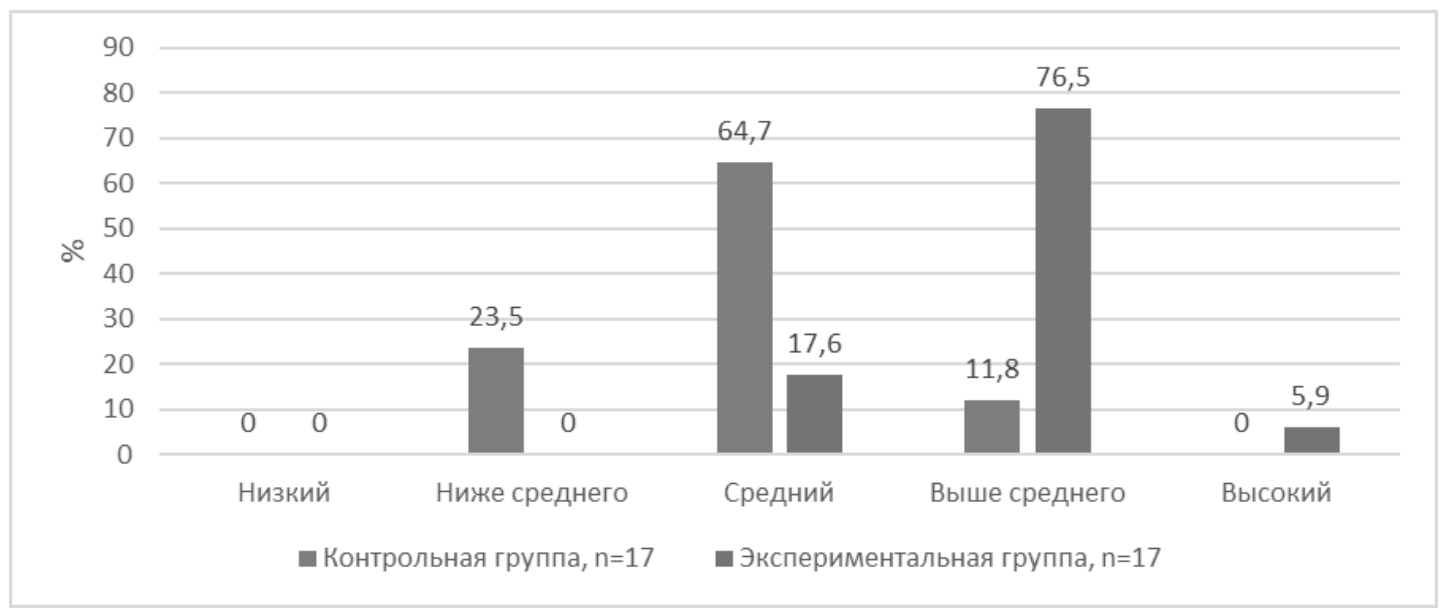

Рис. 1. Уровень физической подготовленности в контрольной и экспериментальной группах после эксперимента (\%)

составил 13,7士1,3раза, а в конце $15,8 \pm 1,1$ раза. После занятий спортивными играми результат повысился на 0,6 раз. Уроки гимнастики улучшили данный показатель еще на 0,6 раза. Лыжная подготовка улучшила показатель на 0,2раза. После легкой атлетики результаты увеличились на 0,4 раза. Прирост составил $11,4 \%$. Результат достоверный при $\mathrm{p}<0,05$.

Сравнение исходных и конечных полученных данных результатов тестирования показали (рис.1), что после проведенного эксперимента уровень физической подготовленности в КГ практически не изменился, и оценивается как «средний», что составляет $64,7 \%$ от общего количества учащихся. Количество учащихся с уровнем физической подготовленности «ниже среднего» осталось без изменений.

Увеличилось число школьников, имеющих уровень подготовленности «выше среднего», их стало 11,8\%. С «высокой» физической подготовленностью учащихся не выявлено. Это объясняется тем, что уровень развития физических качеств в КГ вырос незначительно или остался на прежнем уровне, что подтверждается результатами контрольных срезов в течение года. Поэто- му можно сказать, что традиционные уроки физической культуры носят обучающий поддерживающий характер, а не развивающий.

В ЭГ уровень физической подготовленности заметно вырос. Учащихся с «низким» уровнем и «ниже среднего» после эксперимента не выявлено. Уменьшилось количество учащихся со «средним» уровнем физической подготовленности с 70,6\% до 17,6\%. Число учеников, имеющих уровень подготовленности «выше среднего» значительно увеличилось и составило 76,5\%. Учеников с «высоким» уровнем стало 5,9\% от общего количества испытуемых.

Таким образом, проведенное исследование позволяет судить об эффективности проведения комплексных уроков, в отличие от традиционных, что позволяет динамично, в течение всего года повышать уровень физической подготовленности учащихся среднего школьного возраста. Положительные изменения происходят за счет включения в уроки дополнительных упражнений из различных разделов программы по физической культуре, чем уроки с последовательно-посезонной сменой видов спорта.

\section{ЛИТЕРАТУРА}

1. Иванов В.А., Должников И.В. 0 комплексном развитии физических качеств у школьников //Физическая культура, воспитание, образование, тренировка. - 1998. - №4. - C.10-15.

2. Корниенко А.А. Методы и средства улучшения эффективности физического воспитания в школе //Физическая культура в школе. - 1991. -№3. - С.40-41.

3. Лукьяненко В.П. Современное состояние и концепция реформирования системы общего образования в области физической культуры [Текст]: монография /В.П. Лукьяненко. - М.: Советский спорт, 2005. - 256с.

4. Янсон Ю.А. Уроки физической культуры в школе. Новые педагогические технологии. - Ростов н/Д.: «Феникс, 2005. - 432 с.

( Мельников Юрий Александрович (pffkksi@mail.ru), Феофилактов Николай Зотович (feofilaktov.nikolay@gmail.ru).

Журнал «Современная наука: актуальные проблемы теории и практики» 